\title{
UM INSTRUMENTAL METODOLÓGICO PARA A ANÁLISE DA RELAÇÃO UNIVERSIDADE-GOVERNO NOS PAÍSES DE CAPITALISMO PERIFÉRICO
}

\author{
Rogério Bezerra da Silva* \\ Recebido: 09 maio 2011 \\ Aprovado: 01 jun. 2011
}

* Doutorando em Política Científica e Tecnológica pelo Depto. de Política Científica e Tecnológica do Instituto de Geociências da UNICAMP. Membro do GAPI (Grupo de Análise de Políticas de Inovação) do DPCT/UNICAMP. Bolsista FAPESP. E-mail: rogerio.silva@ige.unicamp.br

Resumo: O problema fundacional da relação entre universidade e governo diz respeito à manutenção dele como fomentador do conhecimento produzido por ela, sem que ele venha a interferir nas autonomias de gestão e de pesquisa dela. Ao se combinar os estudos sobre a universidade dos países periféricos e dos países avançados com as análises do processo de tomada de decisão se pode delinear um instrumental que permita verificar o quanto as autonomias da universidade são constringidas pelo governo. No caso brasileiro, a aplicação desse instrumental mostra que, apesar de tanto se falar sobre a intervenção governamental na universidade, é a própria comunidade de pesquisa, que conta com o apoio dos burocratas das agências de apoio à pesquisa, que ditam os rumos das autonomias da universidade.

Palavras-chave: Universidade. Governo. Autonomia.

\author{
A METHODOLOGICAL INSTRUMENT FOR THE ANALYSIS OF THE \\ UNIVERSITY-GOVERNMENT RELATIONSHIP IN PERIPHERAL COUNTRIES
}

Abstract: The foundational problem of the relationship between university and government concerns the maintenance the government as a fomenter of knowledge produced by the university, without governmental interference in the university's autonomy in management and research. The combination the studies about the university of the peripheral countries and of the advanced countries with the analysis of decision-making process enables us to build the instruments to verify how government creates constraints on the university's autonomy. In the Brazilian case, the application of these instruments shows that, despite all the talk about governmental intervention in the university, it is the very research community, who has the support of the bureaucrats of agencies that support research, that dictates the paths of university autonomy.

Key words: University. Government. Autonomy.

\section{INTRODUÇÃO}

De certa forma, o problema fundamental da relação entre universidade e governo nos países de capitalismo periférico (países periféricos) diz respeito à manutenção dele como o responsável pelos recursos financeiros necessários ao conhecimento científico produzido (à pesquisa produzida) por ela, sem que com isso ele venha a interferir nas autonomias de gestão (independent management) e de pesquisa (academic freedom) dela. 
Esse problema leva à formulação de uma hipótese acerca da relação universidade-governo na periferia do capitalismo. Por um lado, está ocorrendo o aumento da aderência da pesquisa da universidade à demanda cognitiva social (demanda por conhecimento científico) em função de arranjos institucionais que estão levando a um aumento do aporte de recursos financeiros do governo.

Por outro lado, embora haja o aumento dos recursos governamentais para a universidade, não há uma aderência da pesquisa produzida por ela ao que tem sido declarado como prioritário por sucessivos governos no âmbito da Política de Ciência e Tecnologia (PCT) e de outras políticas públicas orientadas ao campo social e ao econômico-produtivo.

Mas, como analisar essa relação entre universidade e governo na periferia do capitalismo? O objetivo deste artigo é justamente buscar construir um instrumental metodológico que permita essa análise.

Ao se combinar os estudos acerca da universidade brasileira e da latinoamericana de forma geral, os estudos acerca da universidade dos países de capitalismo avançado (países avançados) com as análises do processo de tomada de decisão, pode-se construir um instrumental metodológico que permite analisar a relação universidade-governo na periferia do capitalismo.

Este artigo, além desta introdução, possui outras quatro seções. A seção 2 destaca as duas agendas e os quatro projetos políticos em disputa no processo de tomada de decisão acerca da política que deve orientar a relação universidade-governo na periferia do capitalismo. A 3 destaca os modelos cognitivos dos atores universidade e governo presentes na orientação dessa política. O destaque a essas agendas, aos projetos políticos em disputa e aos modelos cognitivos que os fundamenta permite melhor compreender a relação entre universidade e governo.

Na seção 4 se aplica a metodologia construída para o Brasil. Na análise da universidade brasileira se observa que as tendências de sua pesquisa oscilam entre às demandas por qualificação profissional e a produção de conhecimento para as empresas.

A aplicação da metodologia envolveu a consulta aos Relatórios de Gestão da FINEP (Financiadora de Estudos e Projetos do Ministério de Ciência e Tecnologia, do Ministério de Ciência e Tecnologia), do CNPq (Conselho Nacional de Desenvolvimento Científico e Tecnológico, também do Ministério de Ciência Tecnologia) e da CAPES (Coordenação de Aperfeiçoamento de Pessoal de Nível Superior do Ministério da Educação, do Ministério de Educação). Envolveu também revisão bibliográfica acerca da autonomia da universidade. 
E dados das bases SciELO (Scientific Electronic Library Online) e do Diretório dos Grupos de Pesquisa do Brasil do CNPq.

Por fim, as considerações finais destacam que, distinto da percepção de vários autores, a compreensão da relação da universidade com o governo exige ir além das discussões sobre a maior ou menor autonomia financeira dela. Até mesmo porque seria mais conveniente falar em autonomias. Deve-se buscar entender o poder político (politics) da comunidade de pesquisa na orientação das políticas (policy) que envolvem a universidade.

\section{A RELAÇÃO UNIVERSIDADE-GOVERNO NA PERIFERIA DO CAPITALISMO: DUAS AGENDAS E QUATRO PROJETOS POLÍTICOS}

Para se superar a abordagem dicotômica acerca da relação universidadegoverno, em que ora se prioriza a intervenção governamental e ora a da comunidade de pesquisa, se deve considerar na análise dela tanto a policy (políticas públicas) como a politics (relações de poder) presentes nela. Não se pode entender a autonomia da universidade ao se dissociar a policy da politics, presente na relação universidade-governo.

Essa não-dissociação possibilita analisar criticamente a agenda da política buscando evidenciar como ela é determinada pelos interesses e valores dos atores envolvidos com sua elaboração (DAGNINO, 2007; ROTH, 2006; FREY, 2000; HAM; HILL, 1993).

Em função do grau de abertura do sistema político, vários atores (governantes, comunidade de pesquisa, movimentos sociais, administradores etc., em geral não-monolíticos) atuam no processo de tomada de decisão tentando fazer com que sua agenda particular (problemas reconhecidos por meio da combinação dos valores e interesses compartilhados pelos atores) possa ser convertida na agenda da política (conjunto de problemas ou demandas que os que governam admitem, voluntariamente ou sob pressão, e classificam como objetos sobre os quais devem atuar) (DAGNINO, 2007; CAVALCANTI, 2007).

Nem todos os problemas que conformam as agendas particulares dos atores têm a mesma facilidade de fazer parte da agenda da política e, assim, impor aos que governam a necessidade de atuar sobre eles. A força ou debilidade de um ator pode ser avaliada pela sua capacidade de aproximar a agenda da política de sua agenda particular (DAGNINO, 2007).

À medida que um ator entra em interação com outros atores e agendas particulares, no âmbito do processo de tomada de decisão, sua agenda passa 
a dar origem a modelos cognitivos particulares (maneira como o ator percebe a realidade e a partir da qual ele irá descrever, explicar e prescrever acerca do objeto da política e o seu contexto). Pode-se dizer que o modelo cognitivo possui uma relação de realimentação com a agenda particular e com o projeto político do ator.

De fato, dado que a maneira como ator percebe a realidade lhe permite entendê-la de uma forma mais coerente com seu projeto político, mais sintonizada com ela tenderá a ser a sua agenda (DAGNINO, 2007).

Dependendo do poder político do ator, seu modelo cognitivo poderá ser percebido como correto (ser socialmente legitimado) e influenciar decisivamente a forma e o conteúdo da política. No limite, quando um ator consegue impor a sua agenda como a agenda da política, ele consegue enviesar significativamente o processo de tomada de decisão e, com isso, a política incorporará o modelo cognitivo particular dele. O modelo cognitivo do ator passará a ser o "modelo cognitivo da política", o qual servirá de referência para todos os atores intervenientes, levando iterativamente ao fortalecimento do poder dele, que passará a ser dominante no processo (DAGNINO, 2007).

Combinada essa abordagem sobre o processo de tomada de decisão com os estudos acerca da universidade dos países periféricos e dos países avançados, se observa que $\mathrm{o}$ ator comunidade de pesquisa reconhece como problema central de sua agenda a conquista das autonomias de gestão e de pesquisa da universidade pública (TRINDADE, 1999; CHAUÍ, 1999; FÁVERO, 1980; KOURGANOFF, 1990; BOURDIEU, 2003; BRAUN, 1998). Para a comunidade de pesquisa, assegurar essas autonomias é fundamental para o pleno desenvolvimento da universidade.

Esse problema compartilhado pela comunidade de pesquisa (pela universidade) se contrapõe a outro reconhecido pelo governo: tornar a universidade autônoma financeiramente - independente dos recursos financeiros governamentais - , ou então poder orientar sua gestão e sua pesquisa de acordo com a demanda dele.

No embate entre a agenda da universidade e a do governo na periferia do capitalismo, se identifica basicamente quatro posições adotadas por eles acerca da orientação da política que envolve a universidade:

a) Do governo, que por meio da implementação de políticas busca tornar a universidade autônoma financeiramente (independente dos recursos governamentais). Se não, poder interferir em na gestão e na pesquisa dela (MANCEBO, 2004; LESSA, 1999; MANCEBO; SILVA JR., 2004); 
b) Da universidade, favorável à autonomia financeira e à redução de sua autonomia de pesquisa. A comunidade de pesquisa, nesse caso, defende a implementação de políticas que possibilitem à universidade produzir conhecimento para a empresa e, com isso, aumentar suas fontes de recursos (SCHWARTZMAN, 2008; AUDY, 2006);

c) Da universidade, contra políticas que visem torná-la autônoma financeiramente e favorável àquelas que lhe confiram maior autonomia de gestão e de pesquisa (TRINDADE, 2000; GIANNOTTI, 1986; RISTOFF, 1999; CUNHA, 1999; PAULA, 2003);

d) E, da universidade, que acredita que ela sempre foi subordinada ao modo de produção no qual está inserida e, por isso, as políticas governamentais jamais têm como finalidade "libertá-la" (TRAGTENBERG, 1990; ESCOBAR, 2007; MOREL, 1979; FÁVERO, 1980).

Nesse embate, o governo adota uma agenda política da ciência e a universidade luta por uma agenda política para a ciência (SALOMON, 1974).

A política defendida pelo governo (a política da ciência) busca reduzir, ou mesmo suprimir, as autonomias de gestão e de pesquisa da universidade e fazer com que ela atenda à sua demanda cognitiva. Ou torná-la autônoma financeiramente (independe dos recursos dele).

Já a política defendida pela universidade (política para a ciência) busca manter o governo somente como fomentador de sua pesquisa, sem que com isso ele venha a interferir em suas autonomias de gestão e de pesquisa.

Tanto na política da ciência quanto na política para a ciência são observadas ambigüidades, separadas por linhas tênues, que indicam a existência de quatro projetos políticos em disputa (ver Quadro 1).

Tendo autonomias de gestão e de pesquisa, a universidade tem pleno poder e direito de direcionar sua pesquisa e sua gestão segundo os interesses que mais lhe convenham. Se tributária, a universidade tem sua autonomia restringida (não suprimida), pois abre sua pesquisa, ou parte dela, à demanda cognitiva do governo.

Se subordinada, a pesquisa da universidade é determinada pela demanda cognitiva do governo. Cabe à universidade desenvolver a pesquisa demandada por ele. Se não dissociada do governo, a universidade não é mais do que um dos meios de dominação dele. Ou seja, ela é fundamental à manutenção do poder governamental (do Estado). 
Quadro 1 - Agendas dos atores e projetos políticos

\begin{tabular}{|c|c|c|c|}
\hline \multicolumn{2}{|c|}{ Agenda política para a ciência } & \multicolumn{2}{c|}{ Agenda política da ciência } \\
\hline Projeto político & Problema & Projeto político & Problema \\
\hline $\begin{array}{c}\text { Conservar as } \\
\text { autonomias de } \\
\text { gestão e pesquisa } \\
\text { da universidade }\end{array}$ & $\begin{array}{c}\text { A universidade deve } \\
\text { sempre manter } \\
\text { suas autonomias de } \\
\text { pesquisa e de gestão }\end{array}$ & $\begin{array}{c}\text { Tornar a } \\
\text { universidade } \\
\text { subordinada ao } \\
\text { governo }\end{array}$ & $\begin{array}{c}\text { Subordinar a } \\
\text { universidade ao } \\
\text { governo }\end{array}$ \\
\hline $\begin{array}{c}\text { Permitir que a } \\
\text { universidade seja, } \\
\text { no máximo, tributária } \\
\text { ao governo }\end{array}$ & $\begin{array}{c}\text { A universidade pode } \\
\text { ser, no máximo, } \\
\text { tributária do governo }\end{array}$ & $\begin{array}{c}\text { A universidade não } \\
\text { está dissociada do } \\
\text { governo }\end{array}$ & $\begin{array}{c}\text { A universidade } \\
\text { é uma das } \\
\text { manifestações do } \\
\text { poder do governo }\end{array}$ \\
\hline
\end{tabular}

Fonte: Elaboração própria, a partir das proposições de Salomon (1974).

\section{MODELOS COGNITIVOS DOS ATORES E TENDÊNCIAS DA PESQUISA NA UNIVERSIDADE}

Essas agendas e projetos políticos indicam que a universidade tem uma autonomia relativa em relação ao governo. De um lado, o governo busca elaborar políticas que subordinem ou orientem a universidade de acordo com seus modelos cognitivos. Ou seja, elaborar políticas que permitam "mais governo" na gestão e na pesquisa da universidade.

De outro, a universidade atua no processo de tomada de decisão de acordo com a percepção de que as políticas devem torná-la independente do governo ou, no máximo, tributária a ele. Ou seja, para ela deve haver sempre "menos governo" na sua gestão e na produção de conhecimento (em sua pesquisa).

"Mais governo" implica não somente o governo alocar os recursos necessários à universidade como também interferir na gestão e na pesquisa dela. Essa atuação do governo na universidade tem um objetivo: orientar a produção de conhecimento dela para o atendimento da demanda cognitiva dele. E são basicamente três as demandas dele: aquelas pertinentes ao desenvolvimento econômico; as que visam à manutenção de sua soberania nacional; e as de qualificação profissional da população (MANCEBO; MAUÉS; CHAVES, 2006; CHAUÍ, 1999; KLIKSBERG, 1998; MENEZES, 1998; SANTOS FILHO, 2002; PROENÇA JR.; DUARTE, 2007; LESSA, 1999).

Com "menos governo", a universidade além de manter os recursos governamentais na manutenção de suas atividades, diferencia, em certa medida, sua gestão das demais instituições governamentais e orienta sua pesquisa segundo seus próprios interesses (ver Quadro 2). Nesse caso, são basicamente quatro os interesses da comunidade de pesquisa: o que a conecte com ciência interna- 
cional; pela produção de conhecimento para a empresa; o de produzir ciência e tecnologia para o desenvolvimento nacional; o da ciência desinteressada; ou o de produzir conhecimento para a inclusão social (FILGUEIRAS, 2001; SPINAK, 1998; COSTA; CUNHA, 2001; MORAES; STAL, 1994; LEITE LOPES, 1998; VARSAVSKY, 1969; HERRERA, 1975; DAGNINO, 2008; LIANZA; ADDOR; CARVALHO, 2005; BAUMGARTEN, 2006).

A identificação desses modelos cognitivos indica o quanto a produção de conhecimento é tida pelo governo e pela universidade como fundamental para a concreção de seus projetos políticos. E também que existem valores e interesses sociais "embutidos" no conhecimento por ela produzido (DAGNINO e DIAS, 2007).

Quadro 2 - Agendas, projetos políticos, modelos cognitivos e as tendências da pesquisa produzida na universidade

\begin{tabular}{|c|c|c|c|c|}
\hline $\begin{array}{l}\text { Duas } \\
\text { agendas }\end{array}$ & $\begin{array}{l}\text { Quatro } \\
\text { projetos } \\
\text { políticos }\end{array}$ & \multicolumn{2}{|c|}{ Modelo cognitivo dos atores } & $\begin{array}{c}\text { Tendências da } \\
\text { pesquisa }\end{array}$ \\
\hline \multirow{3}{*}{$\begin{array}{c}\text { Política } \\
\text { da ciência }\end{array}$} & $\begin{array}{l}\text { Universidade } \\
\text { não dissociada } \\
\text { do governo }\end{array}$ & \multirow{3}{*}{$\begin{array}{c}\text { A gestão da } \\
\text { universidade } \\
\text { deve ser } \\
\text { identificada a } \\
\text { das demais } \\
\text { instituições } \\
\text { governamentais }\end{array}$} & $\begin{array}{l}\text { A pesquisa } \\
\text { produzida na } \\
\text { universidade } \\
\text { manifesta o poder } \\
\text { do governo }\end{array}$ & $\begin{array}{l}\text { Demandas } \\
\text { orientadas à } \\
\text { qualificação } \\
\text { profissional }\end{array}$ \\
\hline & \multirow{2}{*}{$\begin{array}{l}\text { Universidade } \\
\text { subordinada ao } \\
\text { governo }\end{array}$} & & \multirow{2}{*}{$\begin{array}{l}\text { A pesquisa deve } \\
\text { estar subordinada } \\
\text { ao governo }\end{array}$} & $\begin{array}{l}\text { Demandas do } \\
\text { desenvolvimento }\end{array}$ \\
\hline & & & & $\begin{array}{c}\text { Demandas } \\
\text { da Soberania } \\
\text { Nacional }\end{array}$ \\
\hline \multirow{5}{*}{$\begin{array}{l}\text { Política } \\
\text { para a } \\
\text { ciência }\end{array}$} & \multirow{2}{*}{$\begin{array}{l}\text { Autonomias de } \\
\text { pesquisa e de } \\
\text { gestão }\end{array}$} & \multirow{5}{*}{$\begin{array}{l}\text { A gestão deve } \\
\text { ser definida em } \\
\text { acordo com as } \\
\text { reivindicações } \\
\text { da comunidade } \\
\text { de pesquisa }\end{array}$} & \multirow{3}{*}{$\begin{array}{c}\text { A pesquisa deve } \\
\text { ser determinada } \\
\text { pela comunidade } \\
\text { de pesquisa }\end{array}$} & $\begin{array}{c}\text { Ciência } \\
\text { internacional }\end{array}$ \\
\hline & & & & $\begin{array}{c}\text { Ciência } \\
\text { desinteressada }\end{array}$ \\
\hline & & & & $\begin{array}{c}\text { Produção de } \\
\text { conhecimento } \\
\text { para a empresa }\end{array}$ \\
\hline & \multirow[t]{2}{*}{$\begin{array}{l}\text { Universidade } \\
\text { tributária ao } \\
\text { governo }\end{array}$} & & \multirow[t]{2}{*}{$\begin{array}{c}\text { A pesquisa pode } \\
\text { ser definida com } \\
\text { a participação do } \\
\text { governo }\end{array}$} & $\begin{array}{c}\text { Ciência e } \\
\text { Tecnologia } \\
\text { para o } \\
\text { desenvolvimento } \\
\text { nacional }\end{array}$ \\
\hline & & & & Inclusão social \\
\hline
\end{tabular}

Fonte: Elaboração própria. 


\section{ANALISANDO A RELAÇÃO UNIVERSIDADE-GOVERNO NO BRASIL}

A análise da relação universidade-governo no Brasil se restringirá aos últimos dez anos basicamente, período em que se têm dados disponíveis. Nesse período, observa-se que as tendências da produção de conhecimento oscilam entre a demanda do governo por qualificação profissional e o interesse da comunidade de pesquisa em produzir conhecimento para a empresa.

\section{1 "Medindo" a origem dos recursos financeiros à pesquisa da universidade pública brasileira}

Qual a origem dos recursos que mantém a pesquisa (a produção de conhecimento) da universidade pública brasileira? Para tentar responder essa pergunta, se analisa o comportamento do ator considerado por muitos como aquele que poderia fazer com que a universidade se tornasse autônoma financeiramente: a empresa.

De acordo com dados do Ministério de Ciência e Tecnologia (MCT), entre 2000 e 2009 o governo (nos níveis estaduais e federal) foi responsável por $53 \%$ em média do dispêndio em ciência e tecnologia no Brasil. As empresas inovadoras, por 47\% (MCT.GOV.BR).

As Pesquisas de Inovação Tecnológica (PINTEC) (IBGE, 2003, 2005 e 2008) indicam que, entre 2000 e 2008, 50\% do dispêndio empresarial em atividades de pesquisa foram aplicados na aquisição de máquinas e equipamentos. Ou seja, daqueles $47 \%$ despendidos pelas empresas inovadoras, somente $23,5 \%$ foram aplicados em atividades que necessitam de alguma forma da universidade.

Dessa forma, dos $100 \%$ do dispêndio em ciência e tecnologia no Brasil (público e empresarial) naquelas atividades que necessitam da participação da universidade, $70 \%$ foi de origem pública e 30\% das empresas.

Entre 2006 e 2008 (IBGE, 2008), o principal incentivo público utilizado pelas empresas inovadoras foi o financiamento à compra de máquinas e equipamentos $(14,2 \%)$. E os menos utilizados foram os instrumentos de subvenção econômica $(0,5 \%)$ e o financiamento a projetos de pesquisa e inovação tecnológica em parceria com universidades ou institutos de pesquisa $(0,8 \%)$.

Não somente a universidade tem tido pouca importância para as empresas, como também as atividades de pesquisa não vêm sendo consideradas por elas como estratégias de competitividade. Segundo as PINTEC (IBGE, 2005 e 2008), enquanto 5,6\% das empresas realizaram atividades internas de pesquisa 
em 2005, essa proporção caiu para 4,2\% em 2008. O gasto total da indústria de transformação com atividades de inovação, que era de $2,8 \%$ do faturamento em 2005 , caiu para $2,6 \%$ em 2008 , enquanto a parcela da despesa destinada especificamente à pesquisa intramuros ficou em $0,6 \%$ de seu faturamento em 2008 .

A proporção de empresas que se dedicaram a atividades de pesquisa caiu de $3,9 \%$ para $3,4 \%$ das empresas de pequeno porte, de $16,2 \%$ para $7,9 \%$ das empresas de médio porte e de $44,9 \%$ para $36,3 \%$ das empresas de grande porte entre 2005 e 2008 (KUPFER, 2010).

Ao passo que o emprego na indústria de transformação cresceu $15,2 \%$ entre 2005 e 2008, o número de pessoas com pós-graduação, que era de 4.280 mestres e doutores em 2005, passou para 4.348 em 2008: um aumento de 68 (1,5\%) pesquisadores em três anos (IBGE, 2008).

Entre 2003 e 2006 a FINEP apoiou 600 projetos de cooperação entre universidades (e institutos de pesquisa) com empresas para o desenvolvimento e aperfeiçoamento de produtos ou processos. Foram investidos $\mathrm{R} \$ 600$ milhões por ela, com contrapartida das empresas da ordem de R $\$ 200$ milhões. Ou seja, para cada R $\$ 3$ investidos pela FINEP as empresas investiram R \$ 1 (BAGATTOLLI, 2008).

E, como indica a evolução recente da execução financeira do MCT com o Fundo Nacional de Desenvolvimento Científico e Tecnológico (FNDCT), parece que quanto mais o governo tenta tornar a universidade autônoma financeiramente, mais ele investe nela (ver Gráfico 1).

Gráfico 1 - Execução financeira do FNDCT entre 2002 e 2010

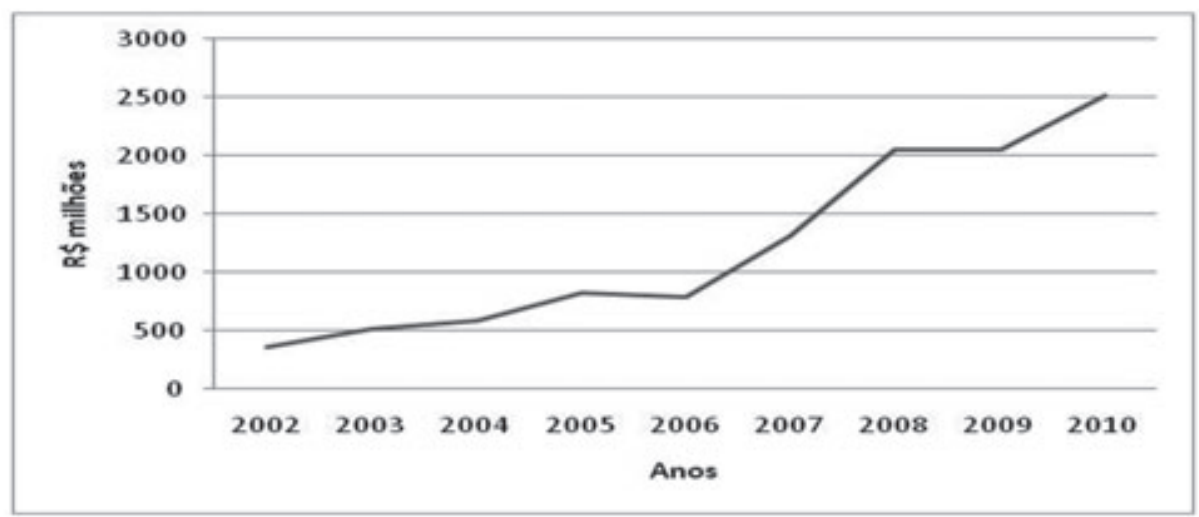

Fonte: MCT (2011). 
Apesar de o governo querer conceder autonomia financeira à universidade, ao que tudo indica, ele continua mantendo-a. Inclusive, aumentando os recursos destinados por ele à pesquisa desenvolvida por ela.

\section{2 "Medindo" a agenda política para a ciência e a agenda política da ciência}

Mas, sendo públicos $70 \%$ dos recursos que mantém a pesquisa da universidade brasileira, o governo também não a orienta segundo sua demanda? Para tentar responder essa pergunta serão utilizados alguns dados das agências de apoio $^{1}$ às atividades de pesquisa ${ }^{2}$ : CNPq, FINEP e CAPES.

Quanto ao CNPq, de seu orçamento líquido entre os anos de 2001 e 2009, cuja média foi de $\mathrm{R} \$ 1,1$ bilhão no período (CNPq, 2010), foram empenhados anualmente R 334 milhões (33\%) em média em ações que podem ser consideradas como de fomento (de atendimento às prioridades elegidas pela própria comunidade de pesquisa) ${ }^{3}$. Outros $57 \%$ respondem à demanda cognitiva do governo.

Isso indica que, do dispêndio total do $\mathrm{CNPq}$ em atividades de pesquisa, $36 \%$ estão voltados à política para a ciência - em que a pesquisa é orientada pela comunidade de pesquisa -, e que $64 \%$ à política da ciência - em que o governo impõe sua demanda à universidade.

Sobre a FINEP, a média de seu esforço operacional entre os anos de 2007 e 2009 ficou em R \$ 2,9 bilhões $^{4}$ (FINEP, 2010). As chamadas e convites, que são pesquisas requisitadas pela própria FINEP, ficaram com 15\% dos recursos empenhados. As encomendas, que apóiam infra-estrutura e projetos definidos pelos conselhos da FINEP, ficaram com $25 \%$ dos recursos. Essas modalidades, que receberam juntas $40 \%$ dos recursos, são aquelas que mantêm uma relação direta da FINEP com a universidade, ligadas à demanda dela.

1 Agências de apoio porque elas poderiam estar respondendo a uma ou outra agenda: seriam fomentadoras da universidade, ou responsáveis por atender as demandas cognitivas do governo.

2 Embora as FAPs (as fundações estaduais de ampara à pesquisa) sejam fundamentais para a pesquisa brasileira (segundo dados do MCT, entre 2000 e 2009, 30\% do dispêndio público com atividades de ciência e tecnologia foram estaduais), por buscar-se aqui tratar do que ocorre no âmbito nacional, elas não serão nesse momento consideradas.

3 Com base nas definições contidas nos PPAs (Planos Plurianuais) do CNPq, seriam elas: Concessão de Bolsas de Estímulo à Pesquisa e Concessão de Bolsas de Iniciação à Pesquisa, que estão nos Programas de Formação e Capacitação de Recursos Humanos para C,T\&I, e de Promoção da Pesquisa e do Desenvolvimento Científico e Tecnológico. Os demais programas e ações corresponderiam às demandas do governo.

4 Aplicados em projetos de pesquisa (nas modalidades de chamada e convites e encomendas), em eventos, na subvenção econômica (nas modalidades projetos de inovação, PAPPE e pesquisador na empresa), em operações de investimentos em Fundos e em operações de crédito (com os programas Inova Brasil e Juro Zero). 
Seu programa de subvenção econômica, que permite a aplicação de recursos públicos não reembolsáveis diretamente nas empresas, ficou com $20 \%$ dos recursos. $\mathrm{O}$ de operações de crédito, que se constituem financiamento público com encargos reduzidos ou a juro zero para a realização de pesquisa nas empresas, recebeu $40 \%$ dos recursos. Juntos, esses dois programas, que são voltados ao estímulo à pesquisa nas empresas, receberam $60 \%$ dos recursos empenhados entre 2007 e 2009 pela FINEP.

Como observado, $60 \%$ do dispêndio da FINEP estão destinados ao atendimento das demandas do governo de forma geral. Outros 40\%, voltados à demanda da própria FINEP. Ou seja, 100\% do dispêndio da FINEP em atividades de pesquisa estão voltados à política da ciência.

Quanto à CAPES, de 2004 a 2009 (CAPES, 2010) seu orçamento médio foi de R $\$ 950$ milhões. Desse total, $87 \%{ }^{5}$ foram empenhados em programas e ações ${ }^{6}$ que podem ser considerados de fomento.

Como declarado pela CAPES, ela "distribui bolsas de mestrado e de doutorado diretamente às universidades [...]. As bolsas são institucionais, o que significa que são distribuídas às instituições, que repassam aos alunos por meio de processo seletivo interno". Então esses $87 \%$ do dispêndio da CAPES são alocados naquelas pesquisas priorizadas pela universidade.

Mas, mesmo diante dessa declaração, ao se analisar os relatórios de gestão da CAPES, algumas de suas ações podem estar voltadas às demandas do governo, quais sejam: Política Industrial, Cooperação Internacional para Educação Básica e Educação Básica - UAB, no programa bolsas de estudo; e Fomento UAB e Fomento Educação Básica, no programa de fomento. Elas representam $18 \%$ do dispêndio da CAPES no período.

Se descontados esses $18 \%$ daqueles $87 \%$ (bolsas mais fomento), pelo menos $69 \%$ do dispêndio da CAPES são destinados ao fomento da universidade. Assim, $80 \%$ dos recursos destinados a programas e ações da CAPES estão voltados à política para a ciência e $20 \%$ à política da ciência.

Uma média das três agências indica que $61 \%$ do dispêndio público em atividades de pesquisa estão voltados à política da ciência e os demais, 39\%, à política para a ciência. Portanto, uma análise restrita aos programas e ações dessas agências indica que na relação universidade-governo ele é não somente

5 Outros 13\% foram empenhados nas atividades/programas de portal de periódicos, avaliação, administração da unidade, administração de pessoal e outras.

6 Seriam eles: Programa Bolsas de Estudo (que contempla as ações de bolsas de estudo no País, Exterior, Política Industrial, Novas Fronteiras, Cooperação Internacional, Cooperação Internacional para Educação Básica, Plano Nacional de Pós-Doutorado, Iniciação à Docência - PIBID - e Educação Básica - UAB), e o Programa de Fomento (que contempla as ações de Fomento à Pós-Graduação, Fomento UAB e Fomento Educação Básica). 
quem aloca os recursos, como também orienta a pesquisa produzida por ela para atender à demanda dele.

Todavia, o governo está de fato orientando a universidade segundo a agenda dele? As autonomias da universidade são constritas? Para tentar responder essas perguntas é necessário analisar os projetos políticos e os modelos cognitivos dos atores intervenientes no processo de tomada de decisão acerca da política que orienta a relação da universidade com o governo.

\subsection{Analisando projetos políticos e modelos cognitivos}

Para analisar projetos políticos e modelos cognitivos presentes na relação universidade-governo se recorre a dois conjuntos de dados: um, sobre as leis, normas e decretos constituídos para regulamentar a universidade; e, outro, sobre a participação dos atores comunidade de pesquisa e governo nas instâncias formais de tomada de decisão acerca das políticas de ciência e tecnologia que, de certa forma, incidem na agenda de pesquisa da universidade.

\subsubsection{A regulação da universidade}

Membros da comunidade de pesquisa dizem que não é tarefa fácil para uma universidade exercer sua autonomia no sistema educacional brasileiro, dado às intervenções e ao controle governamental sobre ela. O governo atua expressivamente sobre a universidade: planeja, define políticas e as executa, legisla, regulamenta e as financia (RANIERI, 1994). Mas, não é fácil mesmo?

No âmbito nacional, se identifica seis marcos importantes na tentativa de regulamentar a universidade ${ }^{7}$ : o primeiro, a Reforma Universitária de 1968 (Reforma de 68); o segundo, a Constituição de 1988; o terceiro, a Lei de Diretrizes e Bases da Educação Nacional, Lei 9.394 de 1996 (LDB); o quarto, o governo Fernando Henrique Cardoso (governo FHC); o quinto, a Medida Provisória (MP) 495 de 2010 junto com os Decretos 7.232, 7.233 e 7.234 de 2010 (governo Lula).

Sobre o primeiro marco, a Reforma de 68 como ficou conhecida a Lei 5.540 promulgada naquele ano, teve grande relevância para a atual configuração da universidade. Essa Lei definiu um conjunto normativo inteiramente inédito para a estruturação e o funcionamento das universidades e demais instituições de ensino superior brasileiras (TRIGUEIRO, 2003).

7 Parece que os anos pares são determinantes para a autonomia universitária. Esses são de fato os pares acadêmicos. 
A Reforma rompeu com o modelo de "cátedras", associou o ensino à pesquisa, introduziu novas atividades acadêmicas (como a extensão e o ensino especial), e definiu regras próprias para a carreira docente, para o acesso do aluno à educação superior e para a organização dos currículos acadêmicos (TRIGUEIRO, 2003).

O segundo marco é a Constituição de 1988, que promulgou um Artigo fundamental para a universidade: o Artigo 207. Ele estabeleceu que as universidades gozariam de autonomia didático-científica, administrativa e de gestão financeira e patrimonial e que obedeceriam ao princípio de não-dissociação entre ensino, pesquisa e extensão.

Segundo Catani e Oliveira (2005), esse é um Artigo muito importante da Constituição para a universidade, uma vez que consagra princípios históricos e acadêmicos fundamentais para a organização e funcionamento dela. Esse Artigo concretiza, portanto, a luta histórica (que se intensificou na década de 1960 e conseguiu vitórias na Reforma de 68) da comunidade de pesquisa na defesa da autonomia universitária, explicitada no princípio da autonomia didáticocientífica, administrativa e de gestão financeira e patrimonial.

Mas, segundo Ranieri (1994), ao mesmo passo em que as leis federais entre 1911 e 1988 concederam autonomia à universidade, elas também foram incapazes de caracterizar a autonomia (de gestão e de pesquisa) como condição da universidade. Em seu conjunto, essa legislação tratava as autonomias da universidade como um privilégio que a qualquer momento seria suprimido.

Com a LDB (terceiro marco) de 1996 se procurou diminuir essa dubiedade. $\mathrm{Na}$ LDB a conceituação de autonomia ficou juridicamente mais clara. Pois, como definido em seu Artigo 54, "as universidades mantidas pelo governo gozariam, na forma da lei, de estatuto jurídico especial para atender às peculiaridades de sua estrutura, organização e financiamento pelo governo, assim como dos seus planos de carreira e do regime jurídico do seu pessoal".

Mas, se juridicamente a autonomia estava mais claramente definida, as contradições do texto constitucional não foram totalmente resolvidas. O trabalho desenvolvido no Congresso Nacional pelo Poder Executivo, que levou à aprovação da LDB, teve um caráter minimalista, pois ele apenas traçou linhas gerais para a universidade, deixando para a legislação complementar seu detalhamento (SGUISSARDI, 2006).

Foi na década de 1990 que a autonomia da universidade começou a ser mais intensamente debatida, em decorrência da ascensão do neoliberalismo. Parece que desde o início dessa década não estava em disputa somente a conquista da 
autonomia de gestão da universidade frente ao controle governamental. Entrou na disputa também se a gestão das universidades devia ser equiparada a das demais instituições estatais (que estavam adotando os mesmo procedimentos gerenciais das empresas privadas) e se elas deviam continuar sendo mantidas com recursos públicos.

Desde essa década, a universidade estava sendo obrigada a aumentar sua eficiência segundo a fórmula: produzir mais e com menores recursos (DIAS SOBRINHO, 2004). A autonomia de gestão concedida à universidade com a ascensão do neoliberalismo consistia em permitir a ela se adequar às necessidades do mercado para a obtenção de recursos extra-orçamentários. Assim como as empresas, a universidade também devia ser gerida segundo critérios econômicos e administrativos privados.

Desde então não é possível ocultar o fato de que as medidas governamentais que visavam estimular a inserção de técnicas de gestão empresarial na universidade e a abertura de sua pesquisa a outros atores têm sido apoiados por parte da comunidade de pesquisa. Segundo Leher (2001), a cumplicidade de parcela da comunidade de pesquisa com as medidas heterônomas (externas à universidade) contribuiu para o esvaziamento do princípio da autonomia da universidade (seja a de gestão ou a de pesquisa).

Desde o primeiro mandato do governo FHC (quarto marco) houve uma série de iniciativas no sentido de equiparar a gestão da universidade a das empresas privadas. Dentre elas se destacam: a Proposta de Emenda à Constituição (PEC) 370 de 1996, que pretendia desconstitucionalizar a autonomia, mas que foi arquivada devido às pressões da comunidade de pesquisa e do Ministério da Fazenda; a Lei 9.131 de 1995, que dispõe sobre a realização do Exame Nacional de Cursos; o Decreto 2.308 de 1997, que regulamenta os Centros Universitários e os Cursos Normais Superiores; a Lei 9.678 de 1998, que cria a Gratificação de Estímulo à Docência; e a Lei 9.962 de 2000, que permite à União contratar docentes e técnico-administrativos na forma do emprego público, regido pela CLT (Consolidação das Leis Trabalhistas).

Em 1999 o Poder Executivo Federal preparou uma minuta de Projeto de Lei para a Autonomia das IFES (Instituições Federais de Ensino Superior). Seu texto dizia que as universidades federais se sujeitariam a mecanismos de controle da sociedade, que verificassem a qualidade e quantidade de serviços prestados por elas (LEHER, 2001).

Embora não mencionasse intervenção, o Projeto previa o bloqueio do repasse de recursos caso o projeto de desenvolvimento institucional não fosse cumprido pelas IFES. Segundo Leher (2001), o Artigo 8 da minuta conferia ao 
Poder Executivo a prerrogativa de limitar a transferência dos recursos para o orçamento das IFES, mesmo após a aprovação deles pelo Congresso.

Todavia, se no início dos anos 2000 parecia que as pretensões da universidade (no caso, as Federais) pela consolidação de sua autonomia de gestão estavam chagando ao fim, ao final desses anos as perspectivas já eram completamente distintas.

Em 2010 foi aprovado um "pacote" normativo (quinto marco) composto pela MP 495 e pelos Decretos 7.232 e 7.233. A MP 495 trata sobre licitações e estabelece as condições de relação das universidades com suas fundações de apoio para os programas de desenvolvimento institucional.

O Decreto 7.232 define que as universidades devem ter autonomia para contratações para repor aposentadorias ou pedidos de exonerações, de forma automática, independentemente de autorização do MEC. E o Decreto 7.233 dá mais autonomia de gestão para as universidades. Elas, inclusive, poderão transferir recursos de um ano para o outro, o que até então era proibido.

Como visto até aqui, há um forte embate entre governo e universidade. Duas questões essenciais sustentam esse embate: uma delas é se a gestão da universidade deve ou não ser assimilada a das demais instituições estatais (e a das empresas); a outra, acerca da origem dos recursos financeiros para a manutenção das atividades da universidade.

Sobre a primeira questão, mais do que por uma ação deliberada do governo, o que orienta esse embate é parcela da comunidade de pesquisa defender "que as universidades não podem ser tratadas como repartições públicas e nem o estatuto do funcionalismo público constitui a forma adequada de gestão para o seu pessoal" e outra parcela que busca "preservar as vantagens e privilégios do serviço público em detrimento da autonomia da universidade" (DURHAM, 2006, p. 4).

Sobre a segunda questão, Otranto (2006), ao analisar a proposta de reforma universitária do governo Lula, observa que a proposta dele apresentava um discurso, à primeira vista sedutor, que ia ao encontro dos anseios da comunidade de pesquisa. Porém, ao lê-los mais atentamente se percebia que a autonomia por ele proposta tinha como enfoque principal a autonomia financeira, ou seja, a "liberação da universidade para captar recursos no mercado, sem amarras legais. Isso dava um enorme alívio financeiro ao Estado que seria obrigado, somente, a complementar esses recursos e não mais teria ele a obrigação de manter financeiramente as universidades públicas" (p. 15).

Ao cabo, o que está presente nesse embate é, de um lado, a busca da comunidade de pesquisa para se desvencilhar das injunções do governo e de garantir 
os recursos públicos necessários à manutenção de sua pesquisa e poder decidir sobre sua própria gestão e, de outro, a tentativa do governo em reduzir seus gastos, liberando a universidade para financiar suas atividades por meio de sua vinculação com as empresas.

Para o governo o que está em questão não é manter o controle sobre a universidade, mas sim reduzir seu dispêndio com ela. Houve uma tentativa - ao que tudo indica, mal sucedida, pois o governo não só continua, como também vêm aumentando os gastos com a universidade — do governo de implementar mecanismos que induzissem a universidade a se tornar autônoma financeiramente.

\subsection{2 "Medindo" a participação dos atores nas instâncias de tomada de decisão}

A formulação da Política Nacional de Ciência, Tecnologia e Inovação (PNCTI), implementada no governo Lula (2003-2010), recebeu importantes contribuições dos debates realizados durante a II Conferência Nacional de Ciência, Tecnologia e Inovação (II CNCTI) de 2001, reunidas no Livro Branco: ciência, tecnologia e inovação, lançado em 2002 (CARVALHO FILHO, 2006).

O Livro Branco apresenta uma "síntese do que os interlocutores da Conferência acordaram: uma agenda de consensos que norteia uma direção" para o "ano de 2012 [que] é o horizonte temporal do Livro" (BRASIL, 2002. p. XVI).

Analisando o perfil dos interlocutores da Conferência (por meio da Memória da Conferência Nacional de Ciência, Tecnologia e Inovação ${ }^{8}$ ), nota-se que $70 \%$ dos 125 expositores, divididos em 30 mesas redondas, pertenciam à comunidade de pesquisa (principalmente cientistas-pesquisadores), 14\% eram representantes do governo (principalmente deputados e secretários estaduais de ciência e tecnologia) e $11 \%$ empresários ( $39 \%$ deles, acadêmicos-empresários $\left.{ }^{9}\right)$.

Outro marco da PNCTI foi a III Conferência Nacional de Ciência Tecnologia e Inovação (III CNCTI), realizada em 2005. A síntese das conclusões e recomendações da III CNCTI foi apresentada no documento III Conferência Nacional de Ciência, Tecnologia e Inovação: síntese das conclusões e recomendações (CARVALHO FILHO, 2006).

Esse documento "baseou-se e beneficiou-se de documentos, notas técnicas e contribuições orais e escritas, apresentadas nos seminários temáticos, conferências regionais e sessões plenárias, antes e durante a III Conferência Nacional de

8 Publicado pelo CGEE (Centro de Gestão e Estudos Estratégicos), na revista Parcerias Estratégicas, n. especial, v. 2, 2002.

9 Cientistas-pesquisadores que abdicaram de seu cargo na universidade para abrir suas próprias empresas (geralmente após terem recebido recursos públicos, via universidade, para abri-las). 
Ciência, Tecnologia e Inovação, pelos colaboradores a seguir relacionado"” 10 (CARVALHO FILHO, 2006). Quem eram esses colaboradores? Dos 157 colaboradores, $69 \%$ pertenciam à comunidade de pesquisa (principalmente cientistas-pesquisadores), $18 \%$ ao governo (deputados, secretários estaduais de ciência e tecnologia e técnicos ministeriais) e $8 \%$ empresários.

Essa III CNCTI, além de ter contado com a "participação ativa de diferentes segmentos da sociedade brasileira, particularmente da comunidade de pesquisa e empresarial", também gerou "contribuições significativas para o aperfeiçoamento e, em alguns aspectos, o redesenho [da PNCTI]; e, em especial, resultou na proposição de ações concretas para sua operacionalização" (CARVALHO FILHO, 2006, p. 25).

Essas ações, baseadas nas contribuições daqueles colaboradores, orientaram os programas do MCT de 2007 a 2010. Pois, como destacado no Plano de Ação 2007-2010 do Ministério, as prioridades dele (e de suas agências de apoio à pesquisa, CNPq e FINEP) "estavam diretamente relacionadas com os quatro eixos estratégicos que nortearam a PNCTI ${ }^{11}$ " (MCT, 2007).

Um órgão importante na legitimação das prioridades do MCT (e, conseqüentemente, das do CNPq e da FINEP) é Conselho Nacional de Ciência e Tecnologia (CCT), instituído pela Lei 9.257 de 1996. Ele é o órgão de assessoramento superior da Presidência da República na tomada de decisão sobre a PNCTI.

Dos 28 representantes de "produtores e usuários de ciência e tecnologia" e de entidades representativas dos setores de ensino e pesquisa (divididos entre titulares e suplentes) que ocuparam o mandato de 2003 a 2010, 52\% pertenciam à comunidade de pesquisa (principalmente cientistas-pesquisadores), 33\% empresários (25\% deles eram acadêmicos-empresários) e $10 \%$ ao governo (secretarias estaduais de ciência e tecnologia).

Na FINEP, um importante órgão de assessoramento estratégico é seu Conselho Consultivo. Dos 67 diferentes integrantes do Conselho (entre membros natos e designados, titulares e suplentes), entre os anos de 2003 e $2010,56 \%$ pertenciam à comunidade de pesquisa (cientistas-pesquisadores), $21 \%$ ao governo (entre técnicos e secretarias estaduais de ciência e tecnologia), $6 \%$ a

10 Ver relação em Carvalho Filho (2006).

11 São elas: expandir, integrar, modernizar e consolidar o Sistema Nacional de Ciência e Tecnologia e Inovação (SNCTI), atuando em articulação com os governos estaduais para ampliar a base científica e tecnológica nacional; atuar de maneira decisiva para acelerar o desenvolvimento de um ambiente favorável à inovação nas empresas, fortalecendo a Política Industrial, Tecnológica e de Comércio Exterior (PITCE); fortalecer as atividades de pesquisa e inovação em áreas estratégicas para a soberania do País, em especial energia, aeroespacial, segurança pública, defesa nacional e Amazônia; e promover a popularização e o ensino de ciências, a universalização do acesso aos bens gerados pela ciência, e a difusão de tecnologias para a melhoria das condições de vida da população. 
empresas (empresários) e 17\% a outras representações (dos trabalhadores e de organizações não governamentais).

O CNPq tem como maior instância de tomada de decisão seu Conselho Deliberativo, que trata principalmente da aplicação de recursos, da definição do orçamento, além da proposição de ações da agência de apoio. Ele tem como membros o presidente e vice-presidente do CNPq, os presidentes da FINEP e da CAPES e o secretário executivo do MCT. Além deles, deveria ter também representantes da comunidade de pesquisa e empresários. Todavia, uma análise dos atuais membros do Conselho mostra que $100 \%$ de seus 18 membros são da comunidade de pesquisa (cientistas-pesquisadores).

Os Fundos Setoriais de Ciência e Tecnologia, criados a partir de 1999, são as principais fontes de recursos à pesquisa no Brasil. Existem hoje 16 Fundos Setoriais, sendo 14 relativos a setores específicos e dois transversais. Uma análise da representação atual dos 16 Fundos mostra que, dos 137 diferentes membros que compuseram todos eles, $48 \%$ pertenciam à comunidade de pesquisa (cientistas-pesquisadores), 29\% ao governo (técnicos do governo, principalmente), 13\% a organizações de representação (organizações não governamentais, principalmente) e $10 \%$ empresários

Na CAPES, um importante órgão é seu Conselho Superior. A análise do perfil dos atuais membros desse Conselho mostra que $75 \%$ deles são da comunidade de pesquisa, $15 \%$ do governo e $10 \%$ de empresas.

Dessa forma, pode ser dito que, se consideradas todas essas instâncias formais de tomada de decisão acerca das políticas de ciência e tecnologia brasileiras, a comunidade de pesquisa tem $71 \%$ de representação nelas, o governo $15 \%$, os empresários $11 \%$ e outros atores $3 \%$.

A autonomia de pesquisa é, de fato, a mais assegurada das autonomias da universidade brasileira. Ela é amplamente preservada porque a comunidade de pesquisa brasileira possui forte representação nos órgãos de avaliação e de apoio público à pesquisa (DURHAM, 2006).

A comunidade de pesquisa parece ter domínio quase que absoluto sobre a pesquisa por ela produzida. Como dito por Schwartzman (1998), "para o bem ou mal", o fato é que a comunidade de pesquisa se apresenta como o mais forte e mais ativo "grupo de interesse" na tomada de decisão acerca da política que orienta a pesquisa da universidade pública brasileira.

Se, de um lado, a comunidade de pesquisa influi sobremaneira na definição da regulação da universidade (tornando a gestão da universidade, inclusive, distinta das demais instituições estatais) e, de outro, é o ator dominante na definição das prioridades das agências de apoio, pode-se assumir que - distinto do que 
foi inferido na seção 4.2 -, está prevalecendo a agenda política para a ciência.

Dessa forma, pode se categorizar o relacionamento entre universidade e governo como ela possuindo autonomias de gestão e de pesquisa ou tributária a ele. Autonomias, pois a comunidade de pesquisa é o ator dominante na definição das políticas que orientam a relação da universidade com o governo. Tributária, pois a comunidade de pesquisa está inserindo em sua pesquisa certas demandas cognitivas daquele ator que, mesmo sendo minoritário nas instâncias de tomada de decisão, se constitui como fomentador das atividades dela: o governo.

\section{4 "Medindo" as tendências da pesquisa da universidade}

Algumas palavras são chave ${ }^{12}$ na identificação de cada uma das oito tendências da agenda de pesquisa da universidade: na agenda política da ciência, a relevância das demandas orientadas à qualificação profissional pode ser "medida" pelas palavras-chave "mão de obra", "qualificação profissional", "formação profissional" e "recursos humanos"; na mesma agenda, demandas do desenvolvimento com as palavras "desenvolvimento econômico", "crescimento econômico" e "desenvolvimento social"; ainda na mesma agenda, demandas da soberania nacional com as palavras "domínio estatal", "dominação estatal", "defesa nacional", "militar" e "soberania nacional".

$\mathrm{Na}$ agenda política para a ciência, a tendência ciência internacional pode ser "medida" por meio das palavras "peer review", "mainstream science", "ciência internacional" e "fronteira do conhecimento". Na mesma agenda, a tendência ciência desinteressada, por meio das palavras "ciência básica", "ciência desinteressada", "ciência universal", "liberdade de pesquisa", "compreensão dos fenômenos" e "descoberta". A tendência produção de conhecimento para as empresas, por meio das palavras "inovação", "universidade-empresa", "competitividade", "empresarial" e "empresa". A ciência e tecnologia para o desenvolvimento nacional, por meio das palavras "desenvolvimento nacional", "interesse nacional" e "subdesenvolvimento". E, por fim, a tendência inclusão social, pelas palavras-chave "sustentabilidade social", "inovação social", "necessidades humanas", "tecnologia social" e "inclusão social".

Para se "medir" cada uma dessas tendências, pode-se recorrer ao número de

12 Essas palavras-chave estão presentes naqueles estudos acerca da universidade na periferia do capitalismo (MANCEBO; MAUÉS; CHAVES, 2006; CHAUÍ, 1999; KLIKSBERG, 1998; MENEZES, 1998 SANTOS FILHO, 2002; PROENCA JR.; DUARTE, 2007; LESSA, 1999; FILGUEIRAS, 2001; SPINAK, 1998; COSTA; CUNHA, 2001; MORAES; STAL, 1994; LEITE LOPES, 1998; VARSAVSKY, 1969; HERRERA, 1975; DAGNINO, 2008; LIANZA; ADDOR; CARVALHO, 2005; BAUMGARTEN, 2006). 
artigos indexados na SciELO, que é a biblioteca eletrônica que abrange uma coleção selecionada de periódicos científicos latino-americanos e caribenhos ${ }^{13}$, e ao Diretório de Grupos de Pesquisa no Brasil do $\mathrm{CNPq}^{14}$, mais especificamente, à produção de CTA dos grupos (ver Quadro 3).

\section{Quadro 3 - Tendências da pesquisa na universidade pública brasileira}

\begin{tabular}{|c|c|c|c|c|c|c|c|}
\hline \multirow[b]{2}{*}{$\begin{array}{l}\text { Tendências da } \\
\text { Pesquisa }\end{array}$} & \multicolumn{4}{|c|}{ Bases de Dados } & \multicolumn{2}{|c|}{ Ocorrências } & \multirow{2}{*}{$\begin{array}{c}\text { Tendência } \\
\text { (\%) }\end{array}$} \\
\hline & ScIELO & $\begin{array}{c}\text { Total } \\
(\%)\end{array}$ & $\begin{array}{l}\text { Produção } \\
\text { de CTA }\end{array}$ & $\begin{array}{c}\text { Total } \\
\text { (\%) }\end{array}$ & Total & $\begin{array}{c}\text { Total } \\
(\%)\end{array}$ & \\
\hline $\begin{array}{l}\text { Demandas por } \\
\text { qualificação } \\
\text { profissional }\end{array}$ & 1218 & 21 & 3979 & 22 & 5197 & 22 & \multirow{3}{*}{35} \\
\hline $\begin{array}{c}\text { Demandas do } \\
\text { desenvolvimento }\end{array}$ & 564 & 10 & 1207 & 7 & 1771 & 7 & \\
\hline $\begin{array}{c}\text { Demandas } \\
\text { da soberania } \\
\text { nacional }\end{array}$ & 286 & 5 & 1155 & 6 & 1441 & 6 & \\
\hline $\begin{array}{c}\text { Ciência } \\
\text { internacional }\end{array}$ & 104 & 2 & 21 & 0 & 125 & 0 & \multirow{6}{*}{65} \\
\hline $\begin{array}{c}\text { Ciência } \\
\text { desinteressada }\end{array}$ & 68 & 1 & 360 & 2 & 428 & 2 & \\
\hline $\begin{array}{c}\text { Produção de } \\
\text { conhecimento } \\
\text { para a empresa }\end{array}$ & 2121 & 36 & 10199 & 55 & 12320 & 50 & \\
\hline & & & & & & & \\
\hline $\begin{array}{c}\text { Ciência e } \\
\text { Tecnologia para o } \\
\text { desenvolvimento } \\
\text { nacional }\end{array}$ & 521 & 9 & 67 & 0 & 588 & 2 & \\
\hline Inclusão social & 1008 & 17 & 1527 & 8 & 2535 & 11 & \\
\hline Total & 5890 & 100 & 18515 & 100 & 24405 & 100 & 100 \\
\hline
\end{tabular}

Fonte: Elaboração própria, a partir de dados da SciELO e Grupos de Pesquisa do CNPq.

13 Essa "medição" deve ser feita por meio do sistema de busca dessa base de dados (Pesquisa de Artigos): utilizando em seu índice (global) o critério país. Feito isso, deve-se manter os critérios todos os índices e Brasil para cada uma das palavras-chave.

14 Para isso, deve-se recorrer ao sistema de busca da base e manter os critérios de busca: Censos 2004, 2006 e 2008, produção de C\&T, título da produção e palavras-chave da produção. Para cada uma das palavras-chave associadas às tendências. 
A SciELO fornece uma idéia de que, embora esses 5.890 artigos correspondam a somente $4 \%$ de todos os artigos publicados na base, a pesquisa está voltada à produção de conhecimento para a empresa (com 36\% dos artigos publicados). $\mathrm{O}$ mesmo ocorre em relação à produção dos grupos de pesquisa do CNPq. Embora essas 18.515 publicações correspondam a somente 5\% das disponíveis na base, elas também indicam uma tendência à produção de conhecimento para a empresa ( $55 \%$ da produção).

Uma média entre as bases permite dizer que, apesar de o governo ser o responsável por $70 \%$ do dispêndio nacional em pesquisa, somente $35 \%$ dela respondem à agenda política da ciência, em que prevalecem as pesquisas orientadas á qualificação profissional (22\%). A grande maioria (65\%) da pesquisa produzida no País atende à agenda política para a ciência, volta à produção de conhecimento para a empresa.

\section{CONSIDERAÇÕES FINAIS}

É comum membros da comunidade de pesquisa afirmarem que seu trabalho está cada vez mais orientado pelo governo. Mas, quando se analisa o processo de tomada de decisão acerca da política que orienta a universidade se constata que a comunidade de pesquisa é o ator dominante nele. O governo se apresenta mais como um fomentador das atividades da universidade (ver Quadro 4).

O fato da comunidade de pesquisa constituir o núcleo do "colégio invisível", associado à prática comum de cientistas-pesquisadores renomados ocuparem posições de comando nas instâncias governamentais formalmente responsáveis pela elaboração da política de apoio à pesquisa, condicionaria também os padrões de comportamento dos burocratas ligados ao processo de tomada de decisão (DAGNINO, 2008).

Apesar de tanto se falar sobre a intervenção governamental na universidade, é a própria comunidade de pesquisa, que contando com o apoio daqueles burocratas das agências de apoio à pesquisa, que dita os rumos das autonomias da universidade.

A pesquisa pela universidade produzida é definida pela própria comunidade de pesquisa. E ela tende a produzir conhecimento para a empresa. Mais do que pela influência das empresas (dos empresários), ao que parece, é a comunidade de pesquisa que direciona (com toda a independência que tem) a pesquisa da universidade para a empresa. 


\section{Quadro 4 - Uma "medida" da relação universidade-governo no Brasil}

\begin{tabular}{|c|c|c|c|c|}
\hline $\begin{array}{c}\text { Duas } \\
\text { agendas }\end{array}$ & $\begin{array}{l}\text { Quatro } \\
\text { projetos } \\
\text { políticos }\end{array}$ & \multicolumn{2}{|c|}{$\begin{array}{l}\text { Modelo cognitivo } \\
\text { prevalecente }\end{array}$} & $\begin{array}{c}\text { Tendências da } \\
\text { pesquisa }\end{array}$ \\
\hline \multirow{3}{*}{$\begin{array}{c}61 \% \text { do } \\
\text { dispêndio } \\
\text { público estão } \\
\text { voltados à } \\
\text { Política da } \\
\text { ciência }\end{array}$} & \multirow{3}{*}{$\begin{array}{c}15 \% \text { de } \\
\text { representantes } \\
\text { do governo } \\
\text { nas instâncias } \\
\text { de tomada de } \\
\text { decisão sobre a } \\
\text { universidade }\end{array}$} & & & $\begin{array}{l}22 \% \text { da pesquisa } \\
\text { da universidade } \\
\text { estão voltados } \\
\text { ao atendimento } \\
\text { das demandas } \\
\text { do governo por } \\
\text { qualificação } \\
\text { profissional }\end{array}$ \\
\hline & & & & $\begin{array}{l}\text { 7\% da pesquisa } \\
\text { estão voltados } \\
\text { às demandas do } \\
\text { governo para o } \\
\text { desenvolvimento }\end{array}$ \\
\hline & & & & $\begin{array}{l}\text { 6\% da pesquisa } \\
\text { estão voltados } \\
\text { às demandas } \\
\text { do governo pela } \\
\text { soberania nacional }\end{array}$ \\
\hline \multirow{5}{*}{$\begin{array}{c}39 \% \text { do } \\
\text { dispêndio } \\
\text { público estão } \\
\text { voltados à } \\
\text { Política para a } \\
\text { ciência }\end{array}$} & \multirow{5}{*}{$\begin{array}{c}71 \% \text { de } \\
\text { representantes } \\
\text { da comunidade } \\
\text { de pesquisa } \\
\text { nas instâncias } \\
\text { de tomada de } \\
\text { decisão sobre a } \\
\text { universidade }\end{array}$} & \multirow{5}{*}{$\begin{array}{c}\text { A gestão deve } \\
\text { ser definida } \\
\text { em acordo } \\
\text { com as } \\
\text { reivindicações } \\
\text { da } \\
\text { comunidade } \\
\text { de pesquisa }\end{array}$} & \multirow{3}{*}{$\begin{array}{c}\text { A pesquisa } \\
\text { deve ser } \\
\text { determinada } \\
\text { pela } \\
\text { comunidade } \\
\text { de pesquisa }\end{array}$} & $\begin{array}{l}\text { 0\% da pesquisa está } \\
\text { voltado à Ciência } \\
\text { internacional }\end{array}$ \\
\hline & & & & $\begin{array}{c}2 \% \text { estão } \\
\text { voltados à Ciência } \\
\text { desinteressada }\end{array}$ \\
\hline & & & & $\begin{array}{c}\text { 50\% da pesquisa } \\
\text { estão voltados } \\
\text { à produção de } \\
\text { conhecimento para a } \\
\text { empresa }\end{array}$ \\
\hline & & & \multirow{2}{*}{$\begin{array}{l}\text { A pesquisa } \\
\text { pode ser } \\
\text { definida } \\
\text { com a } \\
\text { participação } \\
\text { do governo }\end{array}$} & $\begin{array}{c}2 \% \text { da pesquisa } \\
\text { estão voltados à } \\
\text { produção de Ciência } \\
\text { e Tecnologia para } \\
\text { o desenvolvimento } \\
\text { nacional }\end{array}$ \\
\hline & & & & $\begin{array}{l}11 \% \text { da pesquisa } \\
\text { estão voltados à } \\
\text { inclusão social }\end{array}$ \\
\hline
\end{tabular}

Fonte: Elaboração própria. 


\section{REFERÊNCIAS}

AUDY, J.L. Entre a tradição e a renovação: os desafios da Universidade empreendedora. In: AUDY, J.L.; MOROSINI, M.C. (Orgs.). Inovação e empreendedorismo na universidade. Porto Alegre: EDIPUCRS, 2006.

BAGATTOLLI, C. Política científica e tecnológica e a dinâmica inovativa no Brasil, 2008. Dissertação (Mestrado) - Depto. de Política Científica e Tecnológica do Instituto de Geociências da UNICAMP,Campinas, 2008.

BAUNGARTEN, M. Tecnologias sociais e inovação social. Porto Alegre: Portal do Desenvolvimento, 2006.

BOURDIEU, P. El oficio de científico. Barcelona: Editorial Anagrama, 2003.

BRASIL. Livro branco: ciência, tecnologia e inovação. Brasília: Ministério da Ciência e Tecnologia, 2002.

BRAUN, D. The role of funding agencies in the cognitive development of science. Research Policy, Londres, v. 27, 1998.

CAPES. Evolução Orçamentária, 2004 a 2009. 2010. Disponível em: $<$ http://www.capes.gov.br/sobre-a-capes/orcamento $>$. Acesso em: 5 jan. 2011.

CARVALHO FILHO, C.A. Terceira Conferência Nacional de Ciência, Tecnologia e Inovação (C,T\&I). Parcerias Estratégicas, Brasília, n. 19, 2006.

CAVALCANTI, P.A. Sistematizando e comparando os enfoques de avaliação e análise de políticas públicas: uma contribuição para a área educacional. 2007. Tese (Doutorado) - Faculdade de Educação da UNICAMP, Campinas, 2007.

CATANI, A.; OLIVEIRA, J. A Educação superior. 2005.

Disponível em: $<$ http://www.redecaes.com.br/bibliografia_joao/a $\% 20$ educa $\% \mathrm{C} 2 \% \mathrm{~A} 6 \% \mathrm{C} 3 \% 8 \mathrm{Ao} \% 20$ superior.pdf $>$. Acesso em: 10 nov. 2010.

CHAUI, M. A universidade em ruínas. In: TRINDADE, H. (Org.). Universidade em ruínas: na república dos professores. Rio de Janeiro: Vozes, 1999. 
CNPq. Relatórios de Gestão Institucional, 2001 a 2009. 2010. Disponível em: <http://www.cnpq.br/cnpq/relatorio.htm>. Acesso em: 8 jan. 2011.

COSTA, V. M.; CUNHA, J. C. A universidade e a capacitação tecnológica das empresas. Revista de Administração Contemporânea, Rio de Janeiro, v. 5, n. 1, 2001.

CUNHA, L. O público e o privado na educação superior brasileira: fronteira em movimento? In: TRINDADE, H. (Org.). Universidade em ruínas: na república dos professores. Rio de Janeiro: Vozes, 1999.

DAGNINO, R. Ciência e tecnologia no Brasil: o processo decisório e a comunidade de pesquisa. Campinas: Ed. UNICAMP, 2007.

DAGNINO, R. Neutralidade da ciência e determinismo tecnológico: um debate sobre a tecnociência. Campinas: Ed. UNICAMP, 2008.

DIAS SOBRINHO, J. Avaliação ética e política em função da educação como direito público ou como mercadoria? Educação e Sociedade, Campinas, v. 25, n. 88, 2004.

DURHAM, E. A autonomia universitária: extensão e limites. São Paulo: Instituto de Estudos Avançados da USP, 2006.

ESCOBAR, M.R. Universidad, conocimento y subjetividad. Nómadas, Colombia, n. 27, 2007.

FÁVERO, M. Universidade e poder. Rio de Janeiro: Achiamé, 1980.

FILGUEIRAS, C. A história da ciência e o objeto de seu estudo: confrontos entre a ciência periférica, a ciência central e a ciência marginal. Química Nova, São Paulo, v. 24, n. 5, 2001.

FINEP. Relatórios de Gestão, 2007 a 2009. 2010. Disponível em: $<$ http:// www.finep.gov.br/numeros_finep/relatorios_ini.asp $>$. Acesso em: 8 jan. 2011.

FREY, K. Políticas públicas: um debate conceitual e reflexões referentes á prática da análise de políticas públicas no Brasil. Revista de Sociologia e Política, Curitiba, v. 17, n. 15, 2000.

GIANNOTTI, J. A universidade em ritmo de barbárie. São Paulo: Ed. Brasiliense, 1986. 
HAM, C.; HILL M. The policy process in the modern capitalist state. Londres: Harvester Wheatsheaf, 1993.

HERRERA, A. Ciencia y política en América Latina. Argentina: SigloVeinteuno, 1975.

IBGE. Pesquisa Industrial de Inovação Tecnológica (PINTEC). Brasília: IBGE, 2003.

IBGE. Pesquisa Industrial de Inovação Tecnológica (PINTEC). Brasília: IBGE, 2005.

IBGE. Pesquisa Industrial de Inovação Tecnológica (PINTEC). Brasília: IBGE, 2008.

KLIKSBERG, B. Repensando o estado para o desenvolvimento social: superando dogmas e convencionalismos. São Paulo: Cortez, 1998.

KOURGANOFF, W. A face oculta da universidade. São Paulo: Ed. UNESP, 1990.

KUPFER, D. Pintec 2008: primeiras análises. Jornal da Ciência, 03 nov. 2010. Disponível em: <http://www.jornaldaciencia.org.br/Detalhe. jsp?id=74453>. Acesso em: 4 jan. 2011.

LEHER, R. Projetos e modelos de autonomia e privatização das universidades públicas. In: GENTILI. Pablo (Org.). Universidade na penumbra: neoliberalismo e reestruturação universitária. São Paulo: Cortez, 2001.

LEITE LOPES, J. Que ciência para américa latina na era da globalização? CBPF Index, 1998.Disponível em: <http://cbpfindex.cbpf.br/publication pdfs/cs01798.2010_08_17_17_54_58.pdf >. Acesso em: 10 de janeiro de 2010 .

LESSA, C. A universidade e a pós-modernidade: o panorama brasileiro. Dados, Rio de Janeiro, v. 42, n. 1, 1999.

LIANZA, S.; ADDOR, F.; CARVALHO, V. Solidariedade técnica: por uma formação crítica no desenvolvimento tecnológico. In: LIANZA, S.; ADDOR, F. (Orgs.). Tecnologia e desenvolvimento social e solidário. Porto Alegre: Ed.UFRGS, 2005. 
MCT. Relatório de gestão 2010: Fundo Nacional de Desenvolvimento Científico e Tecnológico (FNDCT). MCT: Rio de Janeiro, 2011.

MANCEBO, D.; SILVA JR., J.R. A reforma universitária no contexto de um governo popular democrático: primeiras aproximações. Universidade e Sociedade, Brasília, v. 14, n. 33, 2004.

MANCEBO, D. Reforma universitária: reflexões sobre a privatização e a mercantilização do conhecimento. Educação e Sociedade, Campinas, v. 25, n. 88, 2004.

MANCEBO, D.; MAUÉS, O.; CHAVES, V. L. Crise e reforma do estado e da universidade brasileira: implicações para o trabalho docente. Educar, Curitiba, n. 28, 2006.

MENEZES, D. T. A necessidade de uma política de defesa. Parcerias Estratégicas, Brasília, n. 5, 1998.

MORAES, R.; STAL, E. A situação atual e as perspectivas futuras do relacionamento universidade-empresa no Brasil - algumas experiências concretas. Revista de Administração de Empresas, São Paulo, v. 34, n. 4, 1994.

MOREL, R. Ciência e Estado: a política científica no Brasil. São Paulo: T.A. Queiroz, 1979.

OTRANTO, C. R. A reforma da educação superior do governo Lula: da inspiração à implantação. 2006. Disponível em: <http://www.anped.org.br/ reunioes/29ra/trabalhos/trabalho/GT11-1791--Int.pdf $>$. Acesso em: 10 jan. 2010.

PAULA, M. F. A perda da identidade e da autonomia da universidade brasileira no contexto do neoliberalismo. Avaliação, Campinas, v. 8, n. 4, 2003.

PROENÇA JR, D.; DUARTE, E. E. Os estudos estratégicos como base reflexiva da defesa nacional. Revista Brasileira de Política Internacional, Brasília, v. 50, n. 1, 2007.

RANIERI, N. Autonomia Universitária. São Paulo: EDUSP, 1994.

RISTOFF, D. A tríplice crise da universidade brasileira. In: TRINDADE, H. (Org.). Universidade em ruínas: na república dos professores. Rio de Janeiro: Vozes, 1999. 
ROTH, A. Políticas Públicas: formulación, implementación y evaluación. Bogotá: Ediciones Aurora, 2006.

SALOMON, J. J. Ciencia y política. México: Siglo XXI Editores, 1974.

SANTOS FILHO, J. L. Busca-se a segurança, planeja-se a defesa: uma introdução à (re)discussão dos conceitos de segurança e de defesa nacional na realidade brasileira ontem e hoje. Centro de Estudios Hemisféricos de Defensa, Brasilia, 2002.

SCHWARTZMAN, S. Higher education in Brazil: the stakeholders. Human Resources Department ok World Bank, Estados Unidos, n. 28, 1998.

SCHWARTZMAN, S. Pesquisa universitária no Brasil. In: Centro de Gestão e Estudos Estratégicos. Avaliação de políticas de ciência, tecnologia e inovação: diálogos entre experiências internacionais e brasileiras. Brasília: CGEE, 2008.

SGUISSARDI, V. A avaliação defensiva no "modelo CAPES de avaliação" - É possível conciliar avaliação educativa com processos de regulação e controle do Estado? Perspectiva, Florianópolis, v. 24, n. 1, 2006.

SPINAK, E. Indicadores cienciometricos. Ciência da Informação, Brasília, v. 27, n. 2, 1998.

TRAGTENBERG, M. A Delinqüência Acadêmica. In: TRAGTENBERG, M. Sobre educação, política e sindicalismo. São Paulo: Cortez, 1990.

TRIGUEIRO, M. Reforma universitária e mudanças no ensino superior no Brasil. Brasília: UNESCO, 2003.

TRINDADE, H. As universidades frente à estratégia de governo. In: TRINDADE, H. (Org.). Universidade em ruínas: na república dos professores. Rio de Janeiro: Vozes, 1999.

TRINDADE, H. Saber e poder: os dilemas da universidade brasileira. Estudos Avançados, São Paulo, n. 14, v. 40, 2000.

VARSAVSKY, O. Ciencia, política y cientificismo. Argentina: Centro Editor de América Latina, 1969. 
